\title{
Association of age, sex and deprivation with quality indicators for diabetes: population-based cross sectional survey in primary care
}

\author{
Jeremy Gray ${ }^{1} \quad$ Christopher Millett ${ }^{2,3} \quad$ Caoimhe O'Sullivan ${ }^{5,7} \quad$ Rumana Z Omar6,8 Azeem Majeed ${ }^{4}$
}

J R Soc Med 2006;99:576-581

\section{SUMMARY}

Objectives To determine the quality of diabetes management in primary care after the publication of the National Service Framework and examine the impact of age, gender and deprivation on the achievement of established quality indicators.

Design Population-based cross sectional survey using electronic general practice records carried out between JuneOctober 2003.

Setting Thirty-four practices in Wandsworth, South-West London, UK.

Participants 6035 adult patients ( $\geqslant 18$ years) with diabetes from a total registered population of 201572 patients.

Interventions None.

Main outcome measures Success rates for the diabetes quality indicators within the General Medical Services contract for general practitioners.

Results We identified large variations in diabetes management between general practitioner practices with poorer recording of quality care in younger patients (18-44 years). In addition, younger patients had a worse cholesterol and glycaemia profile, although hypertension was more common in older patients. Gender and deprivation did not appear to be important determinants of the quality of care received.

Conclusions There are large variations in diabetes management between general practitioner practices, with care seemingly worse for younger adults. Longitudinal studies are required to determine whether current UK quality improvement initiatives have been successful in attenuating existing variations in care and treatment outcomes.

${ }^{1}$ Director, ${ }^{2}$ Specialist Trainee in Public Health, Wandsworth Primary Care Research Centre, London SW11 6HN; ${ }^{3}$ Specialist Trainee in Public Health, ${ }^{4}$ Professor of Primary Care, Department of Primary Care \& Social Medicine, Imperial College Faculty of Medicine, London W6 8RP; ${ }^{5}$ Medical Statistician, ${ }^{6}$ Senior Lecturer in Medical Statistics, Medical Statistics Unit, Research \& Development Directorate, University College London Hospitals, London WC1E 5DB; ${ }^{7}$ Medical Statistician, ${ }^{8}$ Senior Lecturer in Medical Statistics, Department of Statistical Science, University College London, London WC1E 6BT, UK

Correspondence to: Christopher Millett, Specialist Trainee in Public Health, Department of Primary Care \& Social Medicine, Imperial College Faculty of Medicine, 3rd Floor, Reynolds Building, St Dunstan's Road, London W6 8RP, UK

E-mail: c.millett@imperial.ac.uk

\section{INTRODUCTION}

Diabetes has been identified as a national priority condition in the UK. Considerable investment has been made to improve the quality of clinical services for individuals with diabetes since 1997. ${ }^{1}$ The National Service Framework for diabetes set out key quality standards to both improve the overall quality of services and address known variations in care. ${ }^{2}$ Financial incentives to improve the management of chronic diseases such as diabetes in primary care were introduced in 2004 as part of the General Medical Services contract.

Early evidence indicates that these initiatives may have led to better management of diabetes in primary care; although the extent of improvement may have been more modest than that achieved for coronary heart disease. ${ }^{3}$ In addition, recent studies highlight persisting variations in the quality of diabetes care being delivered. The General Medical Services quality indicators for diabetes have been shown to be less likely to be achieved for certain sectors of the population, for example in areas of high deprivation and high ethnic mix. ${ }^{4}$ Gender differences have also been identified, with women less likely to have quality care indicators recorded for their diabetes than men. ${ }^{4}$

Reducing differential access to services and treatments across age-groups is clearly important in improving the management of diabetes in primary care. ${ }^{5}$ Age inequalities have been identified in the secondary prevention of coronary heart disease, with older patients less likely to receive effective treatments than younger age-groups. ${ }^{6,7}$ However, few recent studies have examined the relationship between age and the quality of care received for diabetes. We therefore examined associations between age, gender, deprivation and achievement of the General Medical Services quality indicators in adult diabetes patients in one primary care trust in South-West London.

\section{METHODS}

\section{CONDUIT project}

The CONDUIT (Cutting Out Needless Deaths Using Information Technology) programme began in 1998, and was initially piloted in the Battersea Primary Care Group in South-West London. 
Since then the programme has established comprehensive diabetes and coronary heart disease registers within two localities in Wandsworth Primary Care Trust. The data collection period for the present study was June-October 2003. Ethical approval for the study was granted by Wandsworth Local Research Ethics Committee.

\section{Setting and participants}

The two localities contained 40 practices with a total registered population of 245872 . Thirty-four practices participated in the 2003 collection round, providing 82\% coverage of the registered population. The population of Wandsworth is younger than that of England and Wales, with 74\% under 45 years. One in five Wandsworth residents $(22 \%)$ belongs to a non-white minority ethnic group and the borough has high levels of deprivation relative to elsewhere in England (index of multiple deprivation $2004^{8}$ rankings: overall $128 / 354$, income scale 51/354, employment scale 60/354).

\section{Identification of diabetes patients}

The methodology used to develop our disease register for diabetes in Wandsworth has been described previously. ${ }^{9}$ In brief, all patients with type 1 and type 2 diabetes were identified from computerized records by searching diagnosis of diabetes (C10) or diabetes care (66A) Read codes. Patients with repeat prescribing for diabetic medications or with an HbA1c greater than $7.5 \%$ were also included in our sample. Patients under 18 years and women with gestational diabetes were then excluded. Female patients who had no other data relating to diabetes apart from metformin prescribing were excluded on the grounds that they were likely to be receiving treatment for polycystic ovarian syndrome rather than diabetes. Additional verification of the diagnosis of diabetes through hand searching of patient records was not feasible due to the large numbers involved.

\section{Study variables}

We examined quality indicators for diabetes from the General Medical Services contract as they applied to our population between June and October 2003. Each indicator is based on clinical information recorded on the practice computer within the previous 15 months.

Socio-economic status was assigned to individual patients based on their postcode using the Index of Multiple Deprivation 2004. ${ }^{8}$ Patients were then grouped into quintiles, with those in quintile one residing in the most deprived areas and five in the least deprived areas.

\section{Statistical analyses}

We examined variation between general practitioner practices in achievement of each of the quality indicators for diabetes by calculating median values and 10th and 90th centiles. Logistic regression was undertaken to determine odds ratios, with 95\% confidence intervals, for each quality indicator with age, gender and deprivation as the independent variables. We used robust standard errors to take account of the clustering of patients within general practices. $^{10}$ Statistical analyses were performed using STATA 9.1.

\section{RESULTS}

In 2003,6035 adults ( $\geqslant 18$ years) were identified as having diabetes in the 34 participating practices: 3118 were men and 2917 were women. The European age-standardized prevalence of diabetes per 1000 population in all age-groups was 34.5 for females and 38.1 for males. Nearly $70 \%$ of patients were aged 55 years or older (18-44 years [16.6\%], 45-54 years [15.2\%], 55-64 years [24.7\%], 65-74 years [26.6\%], 75+ years [16.9\%]).

The median practice achievement for blood pressure and haemoglobin A1c (HBA1c) recording were 83.6\% and $73.0 \%$, respectively. However, practice achievement of treatment targets was much lower, at $46.2 \%$ for $\mathrm{HbA} 1 \mathrm{c}$ $<7.5$ and $58.3 \%$ for blood pressure $\leqslant 145 / 85$. Considerable between practice variation was evident in the achievement of quality indicators (Table 1).

\section{Age}

Process measures of quality care (Tables 2 and 3) were significantly less likely to be recorded in young adult patients (18-44 years) than in older age-groups. Patients aged 18-44 years were significantly less likely to meet the General Medical Services treatment targets for cholesterol and HbA1c but had better blood pressure control than older patients (Tables 4 and 5).

\section{Gender}

Recording of quality care indicators was broadly similar in men and women. However, women were significantly more likely to be asked about their smoking status than men, but less likely to receive cessation advice if they were smokers.

Women were significantly more likely to have cholesterol levels above $5 \mathrm{mmol} / \mathrm{L}$ but there was no significant difference between women and men in terms of meeting General Medical Services targets for HBA1c control and blood pressure. 
Table 1 Interpractice variation on diabetes quality indicators (\%)

\begin{tabular}{lccc}
\hline & Median & $\begin{array}{l}\text { 10th } \\
\text { centile }\end{array}$ & $\begin{array}{l}\text { 90th } \\
\text { centile }\end{array}$ \\
\hline Diabetes care measures & & & \\
Body mass index measured & 71.9 & 23.4 & 85.5 \\
Smoking status determined & 64.3 & 37.8 & 81.9 \\
Smoking advice provided & 50.5 & 11.8 & 76.2 \\
Hb1Ac measured & 73.0 & 30.8 & 82.9 \\
Blood pressure measured & 83.6 & 50.0 & 94.0 \\
Retinal screening undertaken & 36.8 & 6.3 & 62.2 \\
Pulses measured & 43.8 & 4.5 & 68.5 \\
Cholesterol measured & 69.4 & 20.4 & 82.8 \\
Micro-albuminuria measured & 1.0 & 0.0 & 32.6 \\
Creatinine measured & 72.5 & 26.9 & 88.3 \\
Flu jab administered & 56.0 & 37.3 & 69.1 \\
Outcome measures & & & \\
HbA1c $\leqslant 7.4$ & 46.2 & 31.3 & 58.0 \\
HbA1c $\leqslant 10$ & 89.2 & 84.4 & 93.5 \\
Cholesterol $\leqslant 5$ & 56.3 & 48.1 & 68.8 \\
Blood pressure $\leqslant 145 / 85$ & 58.3 & 46.5 & 68.9 \\
& & & \\
\hline
\end{tabular}

\section{Deprivation}

Recording of quality care indicators was similar in patients within the most and least deprived groups in our sample. Patients in the most deprived group were less likely to meet the General Medical Services target for blood pressure control and more likely to have $\mathrm{HbA} 1 \mathrm{c}>10 \%$ than those in the least deprived groups. However, these differences did not attain statistical significance.

\section{DISCUSSION}

\section{Principal findings}

We identified large variations in diabetes management between general practitioner practices with poorer recording of quality care in younger patients (18-44 years). In addition, younger patients have a worse cholesterol and HBA1c profile, although blood pressure control was better than in older patients. Gender and deprivation did not appear to be important determinants of the quality of care received for most of the indicators. However, control of cholesterol was found to be significantly worse in women.

\section{Strengths and weaknesses of this study}

We identified considerable patient group and practice level variation in the achievement of the General Medical Services quality indicators. Some of this variation may be due to differences in recording practice, rather than the actual differences in the quality of care received. Variations in recording practice in primary care should be gradually eliminated now that the General Medical Services contract has been implemented and general practices are being paid based on the information they are recording.

Table 2 Processes of care recorded in all practices (\%)

\begin{tabular}{|c|c|c|c|c|c|c|c|c|c|c|}
\hline & $\begin{array}{l}\text { Body } \\
\text { mass } \\
\text { index } \\
\text { measured }\end{array}$ & $\begin{array}{l}\text { Smoking } \\
\text { status } \\
\text { determined }\end{array}$ & $\begin{array}{l}\text { Smoking } \\
\text { advice } \\
\text { provided }\end{array}$ & $\begin{array}{l}\text { HbA1c } \\
\text { measured }\end{array}$ & $\begin{array}{l}\text { Blood } \\
\text { pressure } \\
\text { measured }\end{array}$ & $\begin{array}{l}\text { Retinal } \\
\text { screening } \\
\text { undertaken }\end{array}$ & $\begin{array}{l}\text { Pulses } \\
\text { measured }\end{array}$ & $\begin{array}{l}\text { Cholesterol } \\
\text { measured }\end{array}$ & $\begin{array}{l}\text { Micro- } \\
\text { albuminuria } \\
\text { measured }\end{array}$ & $\begin{array}{l}\text { Creatinine } \\
\text { measured }\end{array}$ \\
\hline \multicolumn{11}{|l|}{ Age } \\
\hline $18-44$ & 50.7 & 52.2 & 28.7 & 44.5 & 65.1 & 23.9 & 25.3 & 39.2 & 7.2 & 40.9 \\
\hline $45-54$ & 64.5 & 62.1 & 46.4 & 62.0 & 76.3 & 34.4 & 42.0 & 57.8 & 10.0 & 60.7 \\
\hline $55-64$ & 69.5 & 64.0 & 46.9 & 69.1 & 83.6 & 40.1 & 47.8 & 67.3 & 9.9 & 68.3 \\
\hline $65-74$ & 70.5 & 64.7 & 48.9 & 67.8 & 84.0 & 40.3 & 47.7 & 67.3 & 9.7 & 70.1 \\
\hline $75+$ & 66.7 & 67.8 & 38.5 & 66.0 & 82.5 & 36.4 & 46.4 & 66.0 & 11.1 & 74.0 \\
\hline \multicolumn{11}{|l|}{ Gender } \\
\hline Male & 65.8 & 58.5 & 46.1 & 63.5 & 78.5 & 35.4 & 42.7 & 61.5 & 9.4 & 63.2 \\
\hline Female & 65.0 & 66.9 & 35.2 & 62.6 & 80.3 & 36.6 & 43.2 & 60.4 & 9.8 & 64.9 \\
\hline \multicolumn{11}{|c|}{ Deprivation* } \\
\hline 1 & 71.3 & 66.4 & 47.2 & 68.4 & 83.8 & 38.0 & 44.6 & 64.9 & 12.1 & 69.0 \\
\hline 2 & 60.9 & 60.1 & 39.8 & 57.9 & 75.2 & 34.5 & 40.2 & 56.0 & 10.7 & 59.7 \\
\hline 3 & 65.4 & 62.2 & 40.0 & 62.7 & 81.0 & 35.7 & 43.9 & 59.3 & 10.0 & 62.5 \\
\hline 4 & 64.7 & 62.6 & 42.4 & 64.0 & 78.8 & 37.1 & 42.6 & 61.5 & 7.5 & 62.4 \\
\hline 5 & 64.7 & 61.6 & 39.4 & 62.3 & 78.0 & 34.6 & 43.4 & 63.0 & 7.6 & 66.6 \\
\hline
\end{tabular}


Table 4 Achievement of intermediate outcome indicators (\%)

\begin{tabular}{lllll}
\hline & $\begin{array}{l}\text { Serum } \\
\text { cholesterol } \\
\leqslant \mathbf{5} \text { mmol/L }\end{array}$ & $\begin{array}{l}\text { Blood } \\
\text { pressure } \\
\leqslant \mathbf{1 4 5 / 8 5}\end{array}$ & $\begin{array}{c}\text { HbA1c } \\
\leqslant \mathbf{7 . 4} \%\end{array}$ & $\begin{array}{c}\text { HbA1c } \\
\leqslant \mathbf{1 0} \%\end{array}$ \\
\hline Age & & & & \\
$18-44$ & 54.2 & 75.2 & 39.0 & 86.6 \\
$45-54$ & 53.7 & 57.9 & 46.1 & 85.6 \\
$55-64$ & 56.0 & 55.1 & 43.0 & 87.1 \\
$65-74$ & 59.6 & 57.6 & 49.8 & 89.7 \\
$75+$ & 59.8 & 54.2 & 58.6 & 93.5 \\
Gender & & & & \\
Male & 62.1 & 59.7 & 47.3 & 88.6 \\
Female & 51.9 & 57.8 & 48.2 & 88.7 \\
Deprivation* & & & & \\
1 & 57.3 & 55.9 & 45.3 & 86.4 \\
2 & 55.8 & 59.9 & 48.1 & 88.8 \\
3 & 61.2 & 59.2 & 48.4 & 88.6 \\
4 & 53.6 & 59.7 & 48.7 & 90.4 \\
5 & 58.2 & 59.4 & 48.3 & 89.2 \\
\hline
\end{tabular}

${ }^{*} 1=$ most deprived, $5=$ least deprived

Patients with diabetes were identified from computerized records using algorithms based upon diagnostic and diabetes care codes. We have previously shown that computer searches based on diagnostic Read codes for diabetes alone have a low sensitivity, as they may miss up to a third of cases. ${ }^{9}$ We used a more comprehensive search strategy to compensate for this under-recording of diabetes. All but six general practitioner practices within the study area participated in our survey. Hence our findings provide a comprehensive and typical picture of the care provided in this diverse, inner city location.

\section{Comparison with previous studies}

Few recent studies have examined the relationship between age and the quality of overall diabetes care received. Our findings confirm previous research which has shown that ageing is associated with improved glycaemic control, ${ }^{11-13}$ but an increased likelihood of hypertension. ${ }^{14,15}$ Our findings are also consistent with the recent National Diabetes Audit in England, ${ }^{16}$ which suggested that older patients may be more likely to achieve cholesterol treatment targets. These differences may reflect tighter management policies for older patients within practices and better treatment compliance amongst this patient group. Patients aged $75+$ years did not appear to receive poorer quality care when compared to younger patients. This finding contrasts with recent evidence of persistent age inequalities in the secondary prevention of coronary heart disease. ${ }^{6,7}$

Our findings confirm recent research which suggests that glycaemic control may be similar in women and men, ${ }^{4,11}$ but that women with diabetes are more likely to have poorly controlled cholesterol. ${ }^{4}$ Intermediate treatment outcomes were not significantly different amongst participants living in deprived areas compared with those living in

Table 5 Achievement of intermediate outcome indicators (odds ratios and $95 \%$ confidence intervals for logistic regression models)

\begin{tabular}{|c|c|c|c|c|}
\hline & $\begin{array}{l}\text { Serum cholesterol } \\
\leqslant 5 \mathrm{mmol} / \mathrm{L}\end{array}$ & $\begin{array}{l}\text { Blood pressure } \\
\leqslant 145 / 85\end{array}$ & $\begin{array}{l}\text { HbA1c } \\
\leqslant 7.4 \%\end{array}$ & $\begin{array}{c}H b A 1 c \\
\leqslant 10 \%\end{array}$ \\
\hline \multicolumn{5}{|l|}{ Age } \\
\hline $18-44$ & 1.00 & 1.00 & 1.00 & 1.00 \\
\hline $45-54$ & $0.99[0.76,1.28]$ & $0.45[0.36,0.57]$ & $1.34[1.05,1.70]$ & $0.92[0.62,1.36]$ \\
\hline $55-64$ & $1.10[0.88,1.36]$ & $0.40[0.33,0.49]$ & $1.18[0.93,1.49]$ & $1.05[0.76,1.43]$ \\
\hline $65-74$ & $1.27[1.04,1.55]$ & $0.44[0.36,0.55]$ & $1.55[1.23,1.96]$ & $1.36[0.99,1.87]$ \\
\hline $75+$ & $1.32[1.04,1.69]$ & $0.39[0.30,0.51]$ & $2.21[1.68,2.90]$ & $2.22[1.37,3.61]$ \\
\hline \multicolumn{5}{|l|}{ Gender } \\
\hline Male & 1.00 & 1.00 & 1.00 & 1.00 \\
\hline Female & $0.65[0.56,0.75]$ & $0.93[0.83,1.04]$ & $1.00[0.89,1.13]$ & $0.97[0.78,1.21]$ \\
\hline \multicolumn{5}{|c|}{ Deprivation* } \\
\hline 1 & 1.00 & 1.00 & 1.00 & 1.00 \\
\hline 2 & $0.93[0.76,1.14]$ & $1.21[1.03,1.42]$ & $1.08[0.88,1.32]$ & $1.21[0.93,1.57]$ \\
\hline 3 & $1.16[0.99,1.37]$ & $1.16[0.98,1.37]$ & $1.11[0.93,1.33]$ & $1.20[0.90,1.60]$ \\
\hline 4 & $0.86[0.71,1.04]$ & $1.16[0.96,1.41]$ & $1.15[0.94,1.40]$ & $1.49[1.09,2.03]$ \\
\hline 5 & $1.02[0.81,1.28]$ & $1.18[0.92,1.52]$ & $1.10[0.87,1.38]$ & $1.27[0.97,1.65]$ \\
\hline
\end{tabular}

${ }^{*} 1=$ most deprived, $5=$ least deprived 
more affluent areas. Existing evidence on the association between socio-economic status glycaemic control is mixed $^{4,11,17}$ but may be influenced by definitions used as well as the choice of measurement tool. ${ }^{18}$ Our findings differ from that of Hippisley-Cox et al., ${ }^{4}$ who found that women and patients living in deprived areas may receive less comprehensive care for their diabetes. The comprehensive diabetes disease management programme being implemented in Wandsworth and the regular monitoring of practice performance may have helped to attenuate gender and socio-economic differences in the quality of care for diabetes in this locality.

The European age-standardized prevalence of diabetes per 1000 population in all age-groups was 34.5 for females and 38.1 for males, which is higher than that reported in previous population based surveys. ${ }^{16,19}$ This is not unexpected given that our study population was characterized by a relatively high proportion of individuals from minority ethnic and deprived groups, who are known to experience elevated rates of diabetes. ${ }^{2}$

\section{CONCLUSIONS AND FUTURE RESEARCH}

There is scope to improve the management of diabetes in all age-groups, particularly in younger patients, and address between practice variations in care. Failure to improve diabetes care in younger patients, many of whom will be from ethnic minorities, may lead to an increase in the major complications of diabetes, such as renal failure and peripheral vascular disease, in future years. ${ }^{20}$ Finally, longitudinal studies are required to determine whether current UK quality improvement initiatives are successful in attenuating existing variations in care and treatment outcomes.

Acknowledgments We wish to thank all of the practices that participated in the study and Dr Kamlesh Khunti for providing valuable comments on an earlier draft of this paper. Wandsworth Primary Care Research Centre is funded by the Department of Health.

\section{Competing interests None declared.}

\section{REFERENCES}

1 Leatherman S, Sutherland K. The Quest for Quality In The NHS. A MidTerm Evaluation of The Ten-Year Quality Agenda. London: The Nuffield Trust, 2003

2 Department of Health. National Service Framework for Diabetes. London: DoH, 2001 [http://www.dh.gov.uk/AdvancedSearch/SearchResults/ fs $/$ en $? \mathrm{NP}=1 \& \mathrm{PO} 1=\mathrm{C} \& \mathrm{PI} 1=\mathrm{W} \& \mathrm{PF} 1=\mathrm{A} \& \mathrm{PG}=1 \& \mathrm{RP}=20 \& \mathrm{PT} 1=$ diabetes\&SC $=$ _dh_site $\& Z=1]$ Accessed July 2006
3 Campbell S, Roland M, Middleton E, Reeves D. Improvements in quality of clinical care in English general practice 1998-2003: longitudinal observational study. BMJ 2005;331:1121-5

4 Hippisley-Cox J, O'Hanlon S, Coupland C. Association of deprivation, ethnicity, and sex, with quality indicators for diabetes: population based survey of 53000 patients in primary care. BMJ 2004;329: $1267-70$

5 Department of Health. National Service Framework for Older People. London: DoH 2001 [http://www.dh.gov.uk/AdvancedSearch/ SearchResults $/ \mathrm{fs} / \mathrm{en} ? \mathrm{NP}=1 \& \mathrm{PO} 1=\mathrm{C} \& \mathrm{PI} 1=\mathrm{W} \& \mathrm{PF} 1=\mathrm{A} \& \mathrm{PG}=1 \& \mathrm{RP}=$ 20\&PT1 $=$ older + people\&SC $=$ _dh_site\&Z $=1]$ Accessed July 2006

6 Hippisley-Cox J, Pringle M, Cater R, Coupland C, Meal A. Coronary heart disease prevention and age inequalities: the first year of the National Service Framework for CHD. B J Gen Pract 2005;55:369-75

7 Ramsay S, Morris R, Papacosta O, et al. Secondary prevention of coronary heart disease in older British men: extent of inequalities before and after implementation of the National Service Framework. J Public Health 2005;27:338-43

8 Office of the Deputy Prime Minister. Index of Multiple Deprivation. London: ODPM, 2004 [http://www.communities.gov.uk/index. asp?id=1128440] Accessed July 2006

9 Gray J, Orr D, Majeed A. Use of Read codes in diabetes management in a south London primary care group: implications for establishing disease registers. BMJ 2003;326:1130-3

10 Huber PJ. The behavior of maximum likelihood estimates under nonstandard conditions. In: Proceedings of the Fifth Berkeley Symposium on Mathematical Statistics and Probability Vol. 1. Berkeley: University of California Press, 1967: 221-3

11 Bebb C, Kendrick D, Stewart J, et al. Inequalities in glycemic control in patients with Type 2 diabetes in primary care. Diabetic Med 2005; 22:1364-71

12 Goudswaard A, Stolk R, Zuithoff P, Rutten G. Patient characteristics do not predict poor glycemic control in type 2 diabetes patient treated in primary care. Eur J Epidemiol 2004;19:541-45

13 Koro C, Bourgeois N, Bowlin S, Fedder D. Glycemic control from 1988 to 2000 among US adults diagnosed with Type 2 diabetes. Diabetes Care 2004;27:17-20

14 Hypertension in Diabetes Study Group. HDS 1: Prevalence of hypertension in newly presenting type 2 diabetic patients and the association with risk factors for cardiovascular and diabetic complications. J Hypertens 1993;11:309-17

15 Harris MI, Cowie CC, Stern MP, Boyko EJ, Reiber GE, Bennett PH, eds. Diabetes in America, 2nd edn. Washington: National Institutes of Health, National Institute of Diabetes and Digestive and Kidney Diseases, 1995

16 Health \& Social Care Information Centre. National Diabetes Audit. [http://www.icservices.nhs.uk/ncasp/pages/audit_topics/diabetes/ default-new.asp] Accessed July 2006

17 Chaturvedi N, Jarret J, Shipley M, Fuller J. Socioeconomic gradient in morbidity and mortality in people with diabetes: cohort study findings from the Whitehall study and the WHO multinational study of vascular diseases in diabetes. BMJ 1998;316:100-5

18 Bihan H, Laurent S, Sass C, et al. Association among individual deprivation, glycemic control and diabetes complications. Diabetes Care 2005;28:2680-5

19 Newnham A, Ryan R, Khunti K, Majeed A. Prevalence of diagnosed diabetes mellitus in general practice in England and Wales. Health Stat Q 2002; 14:5-13

20 Stratton I, Adler A, Neil A, et al. Association of glycaemia with macrovascular and microvascular complications of type 2 diabetes (UKPDS 35): prospective observational study. BMJ 2000;321:405-12 